\title{
Recent Concept in Interpreting High-Resolution Manometry
}

\author{
Moo In Park, M.D. \\ Department of Internal Medicine, Kosin University College of Medicine, Busan, Korea
}

Esophageal manometry is considered the gold standard for assessing esophageal motor function. Although conventional manometry has been widely used to evaluate esophageal motor function, this is not fully satisfactory for explaining esophageal symptoms. High-resolution manometry (HRM) is designed to overcome the limitations of conventional manometric systems with advanced technologies. A solid-state HRM assembly with 36 solid-state sensors spaced at $1 \mathrm{~cm}$ intervals (Sierra Scientific Instruments Inc., Los Angeles, CA, USA) has been widely used around the world. Calibration and post-study thermal correction should be performed at each test. The HRM assembly was passed transnasally and positioned to record from the hypopharynx to the stomach. After a 5 minutes resting period to assess basal sphincter pressure, $5 \mathrm{~mL}$ water swallows are obtained in a supine posture. The interpretation of HRM data is still being refined. Recently, the HRM Classification Working Group revised the Chicago classification based on a systematic analysis of motility patterns in 75 control subjects and 400 consecutive patients. The below will show you a summary of the new Chicago classification of distal esophageal motility disorders to provide a practical way of interpreting HRM.

(J Neurogastroenterol Motil 2010;16:90-93)

\section{Key Words}

Esophageal manometry, High-resolution manometry, Esophagogastric junction, Contractile front velocity, Distal contractile integral

ography is depicted in Figure 1.

\section{Introduction}

It is still not established how to interpret HRM data. Some clinicians have analyzed HRM data as conventional line tracings by transforming the pressure topography displays back to conventional line tracings. Recently, the new Chicago classification based on pressure topography was presented to enhance the strengths of the new technology. Typical swallow pressure top-

\begin{abstract}
Algorithm of Analysis Using Pressure Topography Parameters

The HRM Classification Working Group1 proposed a stepwise high-resolution esophageal pressure topography (HREPT) analysis algorithm. First, patients are characterized by esophagogastric junction (EGJ) pressure morphology (presence of hia-
\end{abstract}

Received: December 21st , 2009 Accepted: January 4th, 2010

(c) This is an Open Access article distributed under the terms of the Creative Commons Attribution Non-Commercial License (http://creativecommons. org/licenses/by-nc/3.0) which permits unrestricted non-commercial use, distribution, and reproduction in any medium, provided the original work is properly cited.

*Correspondence: Moo In Park, M.D.

Department of Internal Medicine, Kosin University College of Medicine, 34 Amnam-dong, Seo-gu, Busan 602-702, Korea Tel: +82-51-990-6719, Fax: +82-51-990-5055, E-mail: mipark@ns.kosinmed.or.kr

Financial support: None.

Conflicts of interest: None. 


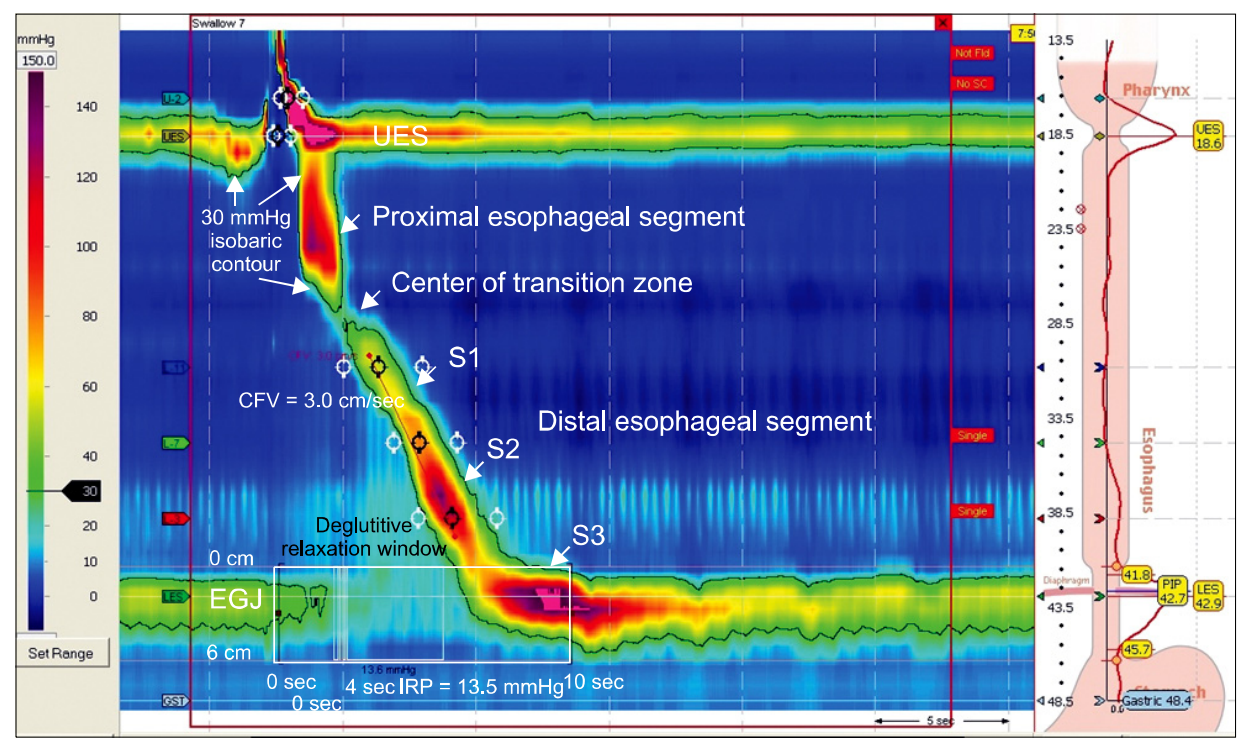

Figure 1. Typical swallow pressure topography spanning from the pharynx to stomach of a normal subject with normal peristalsis and normal esophagogastric junction (EGJ) relaxation. The onset of the deglutitive relaxation window is at the onset of upper sphincter relaxation while the offset is $10 \mathrm{sec}$ later. The spatial domain within which EGJ relaxation is assessed (the eSleeve range) is user defined, spanning at least $6 \mathrm{~cm}$, depending on the extent of esophageal shortening after the swallow. The integrated relaxation pressure (IRP) is a more complex metric of esophagogastric junction (EGJ) relaxation than a simple end expiratory measurement of EGJ pressure after a swallow. The IRP requires persistence of EGJ relaxation for $4 \mathrm{sec}$ within the relaxation window (solid white box) but the actual time periods that go into its calculation (solid gray box) can be contiguous or, non-contiguous. The 4-sec IRP is $13.5 \mathrm{mmHg}$. The transition zone, demarcating the end of the proximal esophageal segment (striated muscle) and the beginning of the distal esophageal segment (smooth muscle), is readily identified as a pressure minimum. Note that the distal segment, in fact, has three sub-segments within it, each with an identifiable pressure peak. The most distal sub-segment, the lower esophageal sphincter, contracts at the termination of peristalsis and then descends back to the level of the crural diaphragm as the period of swallow-related esophageal shortening ends. The characteristics of the distal esophageal contraction are defined by the isobaric contour tool set at $30 \mathrm{mmHg}$ (highlighted with arrows). The isobaric contour can then be utilized to measure the contractile front velocity (CFV) and identify breaks in the contractile wavefront. The CFV is the slope of the line connecting points (red dots) on the $30 \mathrm{mmHg}$ isobaric contour at the proximal margin and the distal margin of the smooth muscle esophagus $(\mathrm{CFV}=3 \mathrm{~cm} / \mathrm{sec})$.

tus hernia) and the presence or absence of impaired deglutitive EGJ relaxation. Second, each swallow is further categorized by the characteristics of the distal esophageal contraction (Table 1). ${ }^{1}$ These measures can now be made with analysis tools available in the current version of ManoViewTM analysis software (version 2.1; Sierra Scientific Instruments Inc.) and Solar GI HRM (Medical Measurement Systems, Enschede, Netherlands). Following the analysis of individual swallows based on the criteria in Table 1, the component results are synthesized into a global diagnosis by the Chicago classification of the distal esophageal mo- tility disorders (Table 2$)^{1}{ }^{1}$

\section{EGJ relaxation}

Many factors can affect deglutitive EGJ relaxation, including crural diaphragm (CD) contractions during respiration, deglutitive esophageal shortening, hiatal hernia, intrabolus pressure (IBP) within the EGJ, sphincter radial asymmetry, and movement of the recording sensor relative to the EGJ. ${ }^{2}$ These difficulties can be greatly improved with HREPT. ${ }^{3}$ Pressure topography plotting defines accurate localization of the EGJ and the 
Table 1. Classification of Individual Swallows Based on Pressure Topography Criteria ${ }^{2}$

\begin{tabular}{|c|c|}
\hline \multicolumn{2}{|r|}{ Distal segment contraction (referenced to atmospheric pressure) } \\
\hline Classification & Criteria \\
\hline Normal & $\begin{array}{l}<3 \mathrm{~cm} \text { defect in the } 30 \mathrm{mmHg} \text { isobaric contour distal to the } \mathrm{TZ} \mathrm{CFV}<8 \mathrm{~cm} / \mathrm{sec} \text {, IBP }<15 \mathrm{mmHg} \text {, } \\
\text { and } \mathrm{DCI}<5,000 \mathrm{mmHg} / \mathrm{sec} \cdot \mathrm{cm}\end{array}$ \\
\hline Hypotensive peristalsis & $\begin{array}{l}\text { Normal appearing wavefront propagation with a } \geq 3 \mathrm{~cm} \text { defect in the } 30 \mathrm{mmHg} \text { isobaric contour distal } \\
\text { to the TZ }\end{array}$ \\
\hline Absent peristalsis & $\begin{array}{l}\text { No propagating contractile wavefront and minimal }(<3 \mathrm{~cm}) \text { contractile activity or pressurization greater } \\
\text { than the } 30 \mathrm{mmHg} \text { isobaric contour }\end{array}$ \\
\hline Hypertensive peristalsis & Normal appearing wavefront propagation with a DCI $>5,000 \mathrm{mmHg} / \mathrm{sec} \cdot \mathrm{cm}$ \\
\hline Spasm & Rapidly propagated contraction ( $\mathrm{CFV} \geq 8 \mathrm{~cm} / \mathrm{sec})$ \\
\hline Elevated IBP & IBP $>15 \mathrm{mmHg}$ compartmentalized between the EGJ and the peristaltic wavefront \\
\hline Pan-esophageal pressurization & Esophageal pressurization from the UES to the EGJ with $>30 \mathrm{mmHg}$ IBP \\
\hline
\end{tabular}

$\mathrm{TZ}$, transition zone; CFV, contractile front velocity; IBP, intrabolus pressure; DCI, distal contractile integral; EGJ, esophagogastric junction; UES, upper esophageal sphincter.

deglutitive relaxation window. The integrated relaxation pressure (IRP) is the lowest average pressure for four contiguous or non-contiguous seconds within the relaxation window. The IRP is the optimal measure for quantifying deglutitive relaxation, with normal being defined as less than $15 \mathrm{mmHg}^{4}$

\section{EGJ morphology}

It has become possible to measure the sphincteric contribution of the CD and LES, and the relative localization of the LES and CD elements using HRM. Characterization of EGJ morphology can be performed using a computer program (MatlabTM, The MathWorks Inc., Natick, MA, USA) customized for processing binary manometric data into isobaric contour pressure plots and spatial pressure variation plots which is not widely available yet. ${ }^{5}$ EGJ morphology can be classified into three types6; type I is characterized by complete overlap of the $\mathrm{CD}$ and the LES. The respiratory inversion point (RIP) lies at the proximal margin of the EGJ. Type II is characterized by minimal, but discernible, LES-CD separation, however the nadir pressure between the LES and CD is still greater than gastric pressure. The RIP is within the EGJ at the proximal margin of the CD. Type III indicates the presence of hiatus hernia. Two subtypes are discernible, IIIa and IIIb, with the distinction being that the RIP is proximal to the CD in IIIa and proximal to the LES in IIIb. The shift in RIP is likely indicative of a grossly patulous hiatus, open throughout the respiratory cycle.

\section{Pressure topography parameters of the distal esophageal segment contraction}

Following the analysis of the EGJ, an individual swallow is further categorized by the characteristics of the distal esophageal contraction. A pressure topography plot highlighting the 30 $\mathrm{mmHg}$ isobaric contour is generated, and then contractile front velocity (CFV) is calculated based on the $30 \mathrm{mmHg}$ isobaric contour plots. Next step is to categorize each swallow into normal, hypotensive, and absent peristalsis. Finally, the distal esophageal contraction is further characterized by the vigour of contraction using a newly developed measure, the distal contractile integral (DCI).

Based on the $30 \mathrm{mmHg}$ isobaric contour, each swallow is characterized as normal (intact $30 \mathrm{mmHg}$ isobaric contour and a $\mathrm{CFV}<8 \mathrm{~cm} / \mathrm{sec}$ ), hypotensive ( $\geq 3 \mathrm{~cm}$ defect in the $30 \mathrm{mmHg}$ isobaric contour), or absent peristalsis (complete failure of contraction with no pressure domain above $30 \mathrm{mmHg}$ ) (Table 1). ${ }^{2}$

Following the analysis of individual swallows, total 10 swallows are classified into three categories: (i) $\geq 70 \%$ normal peristaltic contractions is normal, (ii) $100 \%$ of swallows with absent peristalsis constitutes absent peristalsis, and (iii) $\geq 70 \%$ of swallows with hypotensive peristaltic defects constitutes frequent hypotensive peristalsis (Table 2). ${ }^{2}$ It is notable that the Chicago group abandoned terminology such as peristaltic dysfunction and ineffective esophageal motility. These are not specific enough to describe a hypotensive peristaltic event and could easily include spasm and absent peristalsis.

Once swallows are characterized by the integrity of deglutitive EGJ relaxation and normality of the CFV, the distal esophageal contraction is further characterized for the vigour of contraction using DCI. The DCI integrates the length, contractile vigour, and duration of contraction of the first two sub-segments of the distal esophageal segment contraction, expressed as 
Table 2. The Chicago Classification of Distal Esophageal Motility Disorders $^{2}$

\begin{tabular}{|c|c|}
\hline Disorder & Criteria \\
\hline \multicolumn{2}{|c|}{ With normal EGJ relaxation (mean IRP $<15 \mathrm{mmHg}$ ) and normal IBP } \\
\hline Absent peristalsis & $100 \%$ swallows with absent peristalsis \\
\hline \multicolumn{2}{|l|}{ Hypotensive peristalsis } \\
\hline Intermittent & $\begin{array}{l}\text { More than } 30 \% \text { of swallows with } \\
\text { hypotensive or absent peristalsis }\end{array}$ \\
\hline Frequent & $\begin{array}{l}\geq 70 \% \text { of swallows with hypotensive or } \\
\text { absent peristalsis }\end{array}$ \\
\hline Hypertensive peristalsis & $\begin{array}{l}\text { Normal CFV, mean DCI }>5,000 \text { and } \\
<8,000 \mathrm{mmHg} / \mathrm{sec} \cdot \mathrm{cm} \text { or LES after } \\
\text { contraction }>180 \mathrm{mmHg}\end{array}$ \\
\hline Spastic nutcracker & $\begin{array}{l}\text { Normal CFV, } \\
\text { mean DCI > 8,000 mmHg/sec.cm }\end{array}$ \\
\hline Distal esophageal spasm & $\begin{array}{l}\text { Spasm }(\mathrm{CFV}>8 \mathrm{~cm} / \mathrm{sec}) \text { with } \\
\geq 20 \% \text { of swallows }\end{array}$ \\
\hline Segmental & Spasm limited to $\mathrm{S} 2$ or $\mathrm{S} 3$ \\
\hline Diffuse & Spasm involving both $\mathrm{S} 2$ and $\mathrm{S} 3$ \\
\hline \multicolumn{2}{|c|}{$\begin{array}{l}\text { With impaired EGJ relaxation (IRP } \geq 15 \mathrm{mmHg} \text { ) and/or elevated } \\
\mathrm{IBP}(\text { mean } \geq 15 \mathrm{mmHg})\end{array}$} \\
\hline \multicolumn{2}{|c|}{ Achalasia } \\
\hline Classic achalasia & $\begin{array}{l}\text { Mean IRP } \geq 15 \mathrm{mmHg} \text {, absent } \\
\text { peristalsis }\end{array}$ \\
\hline $\begin{array}{l}\text { Achalasia with } \\
\text { esophageal } \\
\text { compression }\end{array}$ & $\begin{array}{l}\text { Mean IRP } \geq 15 \mathrm{mmHg} \text {, absent } \\
\text { esophageal compressionperistalsis, } \\
\text { and pan-esophageal pressurization } \\
\text { with } \geq 20 \% \text { of swallows }\end{array}$ \\
\hline Spastic achalasia & $\begin{array}{l}\text { Mean IRP } \geq 15 \mathrm{mmHg}, \\
\text { absent peristalsis, and spasm } \\
(\mathrm{CFV}>8 \mathrm{~cm} / \mathrm{sec}) \text { with } \geq 20 \% \text { of } \\
\text { swallows }\end{array}$ \\
\hline $\begin{array}{l}\text { Functional EGJ } \\
\text { obstruction }^{\mathrm{a}}\end{array}$ & $\begin{array}{l}\text { Normal CFV, Max-IBP }>15 \mathrm{mmHg} \\
\text { with } \geq 30 \% \text { of swallows } \\
\text { compartmentalized above EGJ }\end{array}$ \\
\hline
\end{tabular}

${ }^{a}$ May represent an achalasia variant.

EGJ, esophagogastric junction; IRP, integrated relaxation pressure; IBP, intrabolus pressure; $\mathrm{CFV}$, contractile front velocity; DCI, distal contractile integral.

$\mathrm{mmHg} / \mathrm{sec} \cdot \mathrm{cm}^{4}{ }^{4}$ A DCI value greater than $5,000 \mathrm{mmHg} / \mathrm{sec} \cdot \mathrm{cm}$ is considered elevated from an analysis of 75 normal subjects. ${ }^{4}$ Hypertensive peristalsis is consistent with nutcracker esophagus from conventional manometry. Spastic nutcracker defined by a higher threshold DCI $(>8,000 \mathrm{mmHg} / \mathrm{sec} \cdot \mathrm{cm})$, is very rare, found in only $12(3 \%)$ of 400 patient series. ${ }^{7}$ Interestingly, spastic nutcracker is clinically discernible by the uniform association with dysphagia or chest pain. ${ }^{7}$

\section{Conclusion}

It is obvious that performing the test using HRM is more convenient and informs us more data in comparison to the conventional manometry. Although the Chicago classification is an epochal way to understand esophageal motility disorders using HRM data, the validity of the new Chicago classification must be examined by future studies. And the factors considering this new technology should be discussed in terms of performing HRM and interpreting HRM data.

\section{Acknowledgement}

The author thanks Jin-A Park for her assitance in preparing the manuscript.

\section{References}

1. Pandolfino JE, Fox MR, Bredenoord AJ, Kahrilas PJ. High-resolution manometry in clinical practice: utilizing pressure topography to classify oesophageal motility abnormalities. Neurogastroenterol Motil 2009;21:796-806.

2. Pandolfino JE, Kahrilas PJ. AGA technical review on the clinical use of esophageal manometry. Gastroenterology 2005;128:209-224.

3. Clouse RE, Staiano A, Alrakawi A, Haroian L. Application of topographical methods to clinical esophageal manometry. Am J Gastroenterol 2000;95:2720-2730.

4. Ghosh SK, Pandolfino JE, Zhang Q, Jarosz A, Shah N, Kahrilas PJ. Quantifying esophageal peristalsis with high-resolution manometry: a study of 75 asymptomatic volunteers. Am J Physiol Gastrointest Liver Physiol 2006;290:G988-G997.

5. Pandolfino JE, El-Serag HB, Zhang Q, Shah N, Ghosh SK, Kahrilas PJ. Obesity: a challenge to esophagogastric junction integrity. Gastroenterology 2006;130:639-649.

6. Pandolfino JE, Kim H, Ghosh SK, Clarke JO, Zhang Q, Kahrilas PJ. High-resolution manometry of the EGJ: an analysis of crural diaphragm function in GERD. Am J Gastroenterol 2007;102: 1056-1063.

7. Pandolfino JE, Ghosh SK, Rice J, Clarke JO, Kwiatek MA, Kahrilas PJ. Classifying esophageal motility by pressure topography characteristics: a study of 400 patients and 75 controls. Am J Gastroenterol 2008;103:27-37. 